\title{
Numerical Modeling on Assemble-type Composited Wall
}

\author{
Yuanyuan Zhao ${ }^{1,}$, Quan Yuan ${ }^{1, b}$ \\ ${ }^{1}$ Beijing Jiaotong University, Beijing China

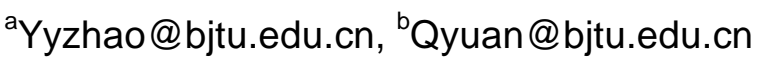

Keywords: assemble-type composited wall, numerical modeling

Abstract. A numerical modeling were built by ABAQUS to do push-over analysis, and the results were consistent with test results in load-displacement curve and frame stress nephogram. Furthermore, the influence of the changing key parameters were analyzed by numerical simulation to understand the axial compression ratio, the aspect ratio and other key parameters how to affect the structure's stiffness, bearing capacity and displacement ductility.

\section{Introduction}

Energy problem is a focus in all of the world, construction may consume one third of the whole energy. During the constructing, labor intensity is huge, construction period is long, and construction effect is low. Along with aging society coming, the construction labor will decrease. In order to build a conservation-minded society, saving energy and decreasing consume became more and more emergency. The development tendency for construction industry will be modularization, standardization and industrialization which can save labor. Prefabrication and site splice will great improve the construction effect, reduce construction period and decrease labor intensity. So developing new structure and component which will suit for the future became urgent.

Industrialized residence system using assemble-type composited wall is a new system. Assemble-type composited wall is the main load-bearing component in the system, and the wall also can be used as a heat preservation surround wall. The wall is a composed structure which composed with steel frame and filled foam cement. Steel frame composed with rib-beams, rib-column and invisible frame. The ultimate bearing capacity and seismic performance are the most important thing affecting the wall can be industrialized or not. Because of the wall is a new composed structure, the character of assemble-type composited wall is different from the traditional one. So we did a numerical modeling to simulate the new structure.

\section{Nonlinear finite element model established}

We adopt a finite element software named ABAQUS to carry through numerical analysis. The element type defined as table 1.

\begin{tabular}{ccc} 
& \multicolumn{2}{c}{ Table 1 element type } \\
\hline Material & Element type & note \\
\hline bar & T3D2 & 2 node, 3 dimension, linear \\
concrete & C3D8R & frame-beam, frame-column, rib-beam, rib-column \\
foam cement & C3D8R & foam cement \\
\hline
\end{tabular}

Interaction effect between block and rib, also rib and frame included two parts: one was normal effect, the other was tangential effect. Tangential included relative movement between contact surfaces, this interaction was on behalf of a character, and it defined a model of the interaction effect. The grid accuracy included block, rib and frame was approximately the same. According the rule, the interaction between block and rib, we selected the block surface as the dependence, the rib surface as the master. The interaction between rib and frame, we selected the rib surface as the dependence, the frame surface as the master. The sketch map showed as fig.1. 


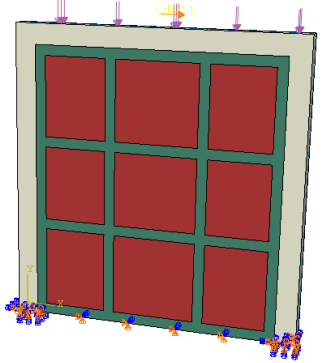

Fig. 1 numerical model of assemble-type composited wall

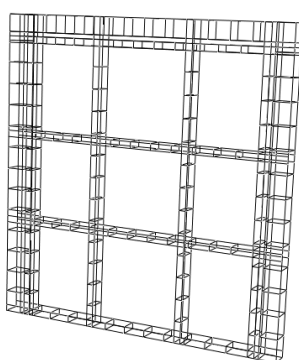

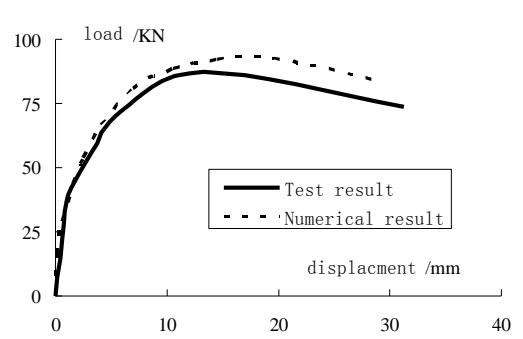

Fig.2 load result comparison

(1) Load-displacement curve

For ECW-1, the comparison between test result and numerical result on skeleton curve showed in fig.2.

We can get the result that:

1) The numerical result and the test result matched each other at the beginning, there was some deviation in the elastic period, but the deviation was very small. So the numerical model was suitable and accurate for the assemble-type composited wall to some extent.

2) The numerical result was slightly bigger the test result in the elastic-plastic period, the reason was that: The loading condition was better in numerical than that in real test where there was some deviation in vertical and horizon load. We did not consider the defect on the gap between the blocks and the initial imperfection. The friction coefficient was get in pertinent literature which was not match very well.

(2) The internal force regularities of distribution

For ECW-1, the frame stress nephogram was showed as fig.3.

Form the frame stress nephogram we can get: during the last phase, the stress in rib-beam bar was large, most of them yielded, the stress in rib-column bar was small, and the stress in the intersection bar between rib-beam and rib-column was bigger than other place. So the intersection formed plastic hinge which also verified that the numerical model was suitable and accurate.

In conclusion, use ABAQUS to do nonlinear analysis on assemble-type composited wall can really simulate the change of the internal force in the wall, confirm the ultimate bearing capacity and the displacement. This was accurately and useful for engineering design and theoretical research.

\section{Nonlinear finite element model extension analyzed on assemble-type composited wall}

There were lots of element which can affect assemble-type composited wall, but the key parameters were axial compression ratio and aspect ratio. So we did extension numerical analyze based on ECW-1 and understood the axial compression ratio, the aspect ratio and other key parameters how to affect the anti-seismic property. Also provided reference frame to establish design methods on assemble-type composited wall.

Specimens' No. and specimens' characteristic were showed as table 2.

\section{Compared to numerical result and test result}

1. load-displacement curve

\begin{tabular}{ccc} 
Table 2 specimen design \\
\hline group & axial compression ratio: $\mathrm{n}$ & aspect ratio: $\lambda$ \\
\hline (a) & $0.23 、 0.35 、 0.46$ & 1 \\
(b) & 0.23 & $1,2 、 3$ \\
\hline
\end{tabular}

From the skeleton curve fig.5 under different axial compression ratio and aspect ratio, different working conditions, different walls, we can get:

1) Under different working conditions, all different specimens skeleton curve had the dissymmetry curve. Forward and reverse tension compression bearing capacity was basic the same. This indicated 
that under low cycle load, the block in assemble-type composited wall specimens could craze and close effectively, the rib and frame deformed compatibly, worked cooperatively, bear load together.

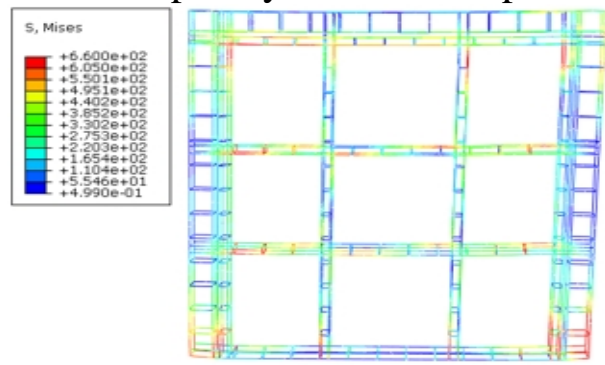

Fig.3 frame stress nephogram
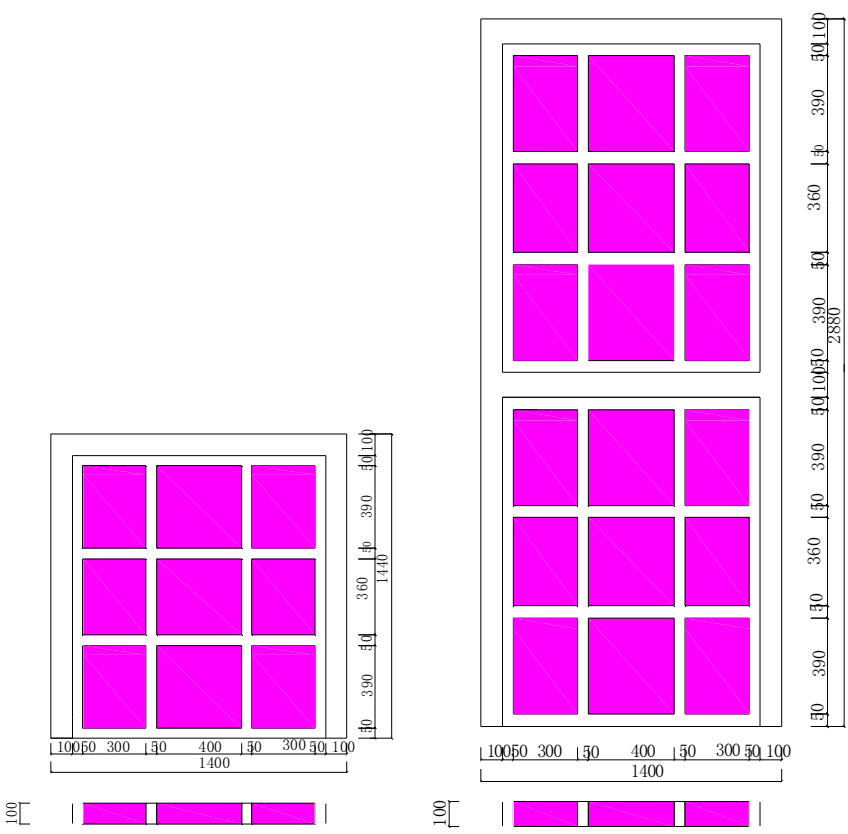

(a) $(\mathrm{n}=0.23 / 0.35 / 0.46, \lambda=1)$

(b) $\quad(n=0.23, \lambda=2)$

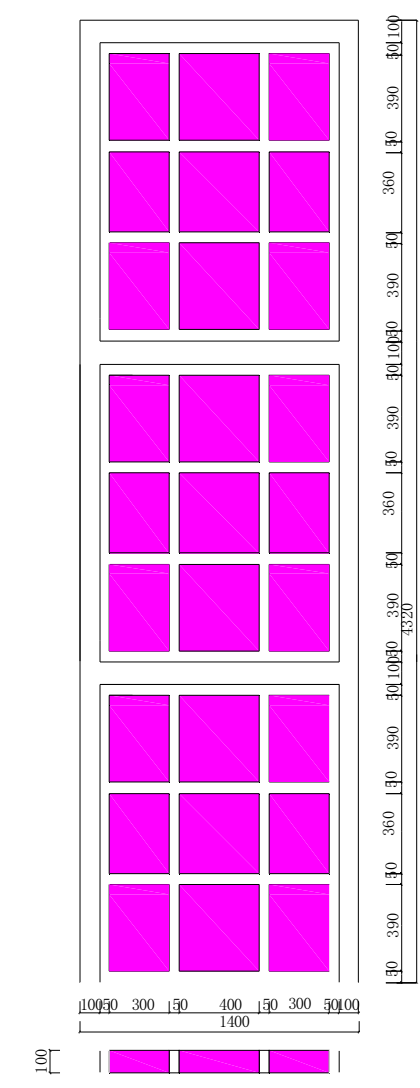

Fig.4 Specimen sketch map

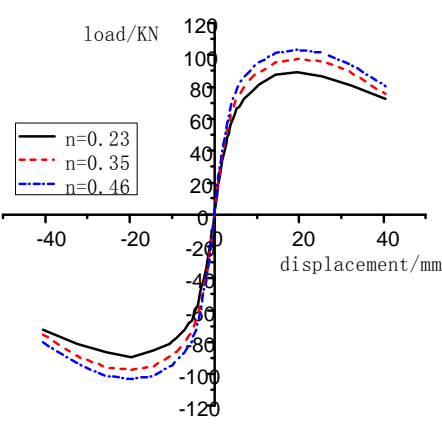

(a) $\lambda=1.03$

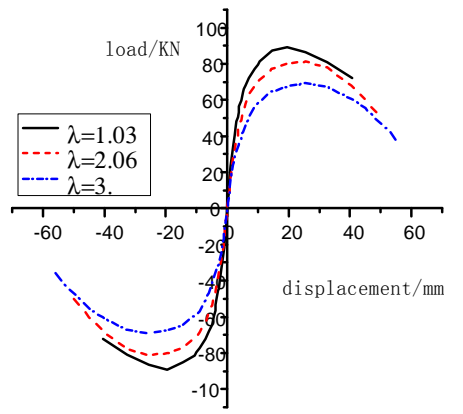

(b) $\mathrm{n}=0.23$

Fig.5 comparison on skeleton curve

2) Under different working conditions, all different specimen went through elastic, elastic-plastic and failure procedure. From beginning to yield, the skeleton curve changed gently, no jumping, indicated that bearing capacity rised and descented gently, all different material gave full play to their mechanical property, the ductility of wall was good.

2. feature load and ductility

The feature load and ductility of every wall under different work situation was showed as table 3 . 
From table 3, we can get that:

1) The affect by axial compression ratio

The affection on shear capacity and ductility by axial compression ratio from five different specimens showed the same rule: Along with the increase of axial compression ratio, the oblique section shear capacity increased, but the rate of increase diminished. The reason showed as follow: the increased axis load effectively constrained diagonal cracks appearing, enhanced entirety cooperative work performance, increased diagonal shear capacity. But when the axis load attached the certainly value, the bearing capacity controlled by the material property, at this period, the bearing capacity wasn't increase. In a similar way, when the axis load exceeded a certain value, the ductility of the specimen was reduce in varying degrees. In conclusion, axial compression ratio obviously affected shear capacity and ductility on assemble-type composited wall. The sharing capacity and ductility of the wall increased when the axial compression ratio in a certain range, conversely, it decreased.

Table 3 feather load and ductility of specimens

\begin{tabular}{|c|c|c|c|c|c|c|c|c|}
\hline \multicolumn{2}{|c|}{ No. } & $\begin{array}{r}\text { Yield } \\
\text { load } P_{y} \\
\mathrm{kN} \\
\end{array}$ & $\begin{array}{c}\text { Yield } \\
\text { displaceme } \\
\text { nt } \Delta_{y} \\
\mathrm{~mm} \\
\end{array}$ & $\begin{array}{c}\text { Ultimate } \\
\text { load } P_{w} \\
\mathrm{kN} \\
\end{array}$ & $\begin{array}{c}\text { Ultimate } \\
\text { displaceme } \\
\mathrm{nt} \Delta_{w} \\
\mathrm{~mm}\end{array}$ & $\begin{array}{c}\text { Failure } \\
\text { load } P_{u} \\
\mathrm{kN} \\
\end{array}$ & $\begin{array}{c}\text { Failure } \\
\text { displaceme } \\
\mathrm{nt} \Delta_{u} \\
\mathrm{~mm}\end{array}$ & $\begin{array}{c}\text { Ductility } \\
\text { ratio } \\
\Delta_{u} / \Delta_{y}\end{array}$ \\
\hline \multirow{3}{*}{$\begin{array}{c}(\mathrm{a}) \\
\lambda=1.03\end{array}$} & $\mathrm{n}=0.23$ & 70.3 & 7.7 & 89.5 & 21.7 & 76.1 & 38.1 & 5.1 \\
\hline & $\mathrm{n}=0.35$ & 74.8 & 7.1 & 97.3 & 17.4 & 82.7 & 35.6 & 5.0 \\
\hline & $\mathrm{n}=0.46$ & 77.5 & 6.8 & 103.1 & 15.6 & 86.2 & 33.9 & 4.9 \\
\hline \multirow{3}{*}{$\begin{array}{c}(b) \\
\mathrm{n}=0.23\end{array}$} & $\lambda=1.03$ & 70.3 & 7.7 & 89.5 & 21.7 & 76.1 & 38.1 & 5.1 \\
\hline & $\lambda=2.06$ & 67.8 & 8.3 & 81.3 & 25.6 & 69.1 & 45.6 & 5.5 \\
\hline & $\lambda=3.1$ & 58.4 & 9.1 & 69.3 & 27.2 & 58.9 & 52.5 & 5.8 \\
\hline
\end{tabular}

Note: 1) Yield load: Adopted energy equivalents method to ensure the point of the equal point which corresponding to the yield load.

2) Ultimate load: adopted forward and reverse ultimate load absolute average value as the ultimate load.

3) Failure load: adopted $85 \%$ of the max load.

4) Ductility ratio: the ratio the placement where the skeleton curve dropped to $85 \%$ to the yield displacement

2) The affect by aspect ratio

The affection on shear capacity and ductility by aspect ratio from five different specimens showed the same rule: Along with the increase of aspect ratio, the oblique section shear capacity decreased. The reason showed as follow: Along with the increase of aspect ratio, the failure mode became to shear-bending from shear type, the specimens constrained decreased by vertical frame-column, which caused the share capacity decreased. Along with the aspect ratio increase, the ductility increased when the aspect ratio in a certain range. In conclusion, in a certain range, along with the increase of aspect ratio, the share capacity decreased and the ductility increased on assemble-type composited wall.

\section{Conclusion}

A numerical modeling were built by ABAQUS to do push-over analysis, and the results were consistent with test results well, it can be used in analyzing the influence of the changing key parameters on assemble-type composited wall. Axial compression ratio obviously affected shear capacity and ductility on assemble-type composited wall. The sharing capacity and ductility of the wall increased when the axial compression ratio in a certain range, conversely, it decreased. In a certain range, along with the increase of aspect ratio, the share capacity decreased and the ductility increased on assemble-type composited wall.

\section{References}

[1] Forward-looking industry research institute: Intelligent building industry market prospect and investment strategic planning analysis report in China during the year 2013-1017 (2013)

[2] Xi'an University of Architecture and Technology: science and technology report: theory and application research on multi-ribbed wall slab light-weight frame structure (2000) 
[3] Qianfeng Yao, Ping Chen, Ying Zhang and Dong Zhao: Study on Energy-saving Residential System of Multi-ribbed Wall Slab with Light-weight Outer Frame. Industrial Construction (2003), Vol.33, No.1, p1-5

[4] Qianfeng Yao: Research and Development on New Energy-saving Structural System. Engineering mechanics. (2001), Supplement, p138-155 